\title{
High Performance Dual Ballistic and Thermal Neutrons Shields From Kevlar Fibers Reinforced Epoxy/B $\mathbf{H}_{4} \mathrm{C}$ Hybrid Composites
}

\author{
Mehdi Derradji *, Oussama Mehelli, Raouf Belgacemi and Slimane Abdous \\ Laboratoire Génie des Procédés, UER Procédés Energétiques, Ecole Militaire Polytechnique, Algiers, Algeria
}

Targeting the development of advanced lightweight thermal and ballistic neutrons shields, a new hybrid composite was developed, for the first time, from Kevlar fibers, epoxy and boron carbide $\left(\mathrm{B}_{4} \mathrm{C}\right)$ particles. Kevlar fibers, as one of the strongest polymeric fillers, possess a high proportion of low Z atoms highly suitable for moderating neutrons. Meanwhile, these fibers can provide an additional efficient protection against high velocity projectiles. The $\mathrm{B}_{4} \mathrm{C}$ particles were added in various amounts, mainly for their excellent absorption of thermal neutrons. The nuclear shielding tests were performed at NUR research reactor using an optimized experimental setup. The obtained results confirmed the high shielding efficiency of all the developed materials. Meanwhile, the best performance was recorded at $\mathrm{B}_{4} \mathrm{C}$ amount of 20 wt.\% with a macroscopic cross-section $(\Sigma)$ of with a $3.638 \mathrm{~cm}^{-1}$ equivalent to a mean free path $(\lambda)$ of $0.191 \mathrm{~cm}$. The obtained results were compared with the most performant available shields and the data confirmed that superiority of the developed materials.

Keywords: nuclear materials, polymers, radiation damage 2, neutrons, nuclear reactor (NR)

\section{INTRODUCTION}

Neutrons, as the most penetrating particles, have found applications in many sectors nuclear including but not limited to nuclear power plants, medical hospitals, radiography and aerospace. To safely take advantage of these highly ionizing radiations, proper shielding materials need to be developed to protect the personals and properties. The currently available shielding materials mainly consist of water and concrete. Although these materials are efficient neutrons shields, they cannot be adapted to provide wearable and lightweight protective gears for personal working in the vicinity of these radiations.

Among low $\mathrm{Z}$ materials, polymeric fibers have gained a lot of attention in the field of nuclear shielding due to their exceptional lightweight and ease of transformation into various shapes. Among these remarkable fillers, Ultra High Molecular Weight (UHMWPE) fibers have been proven to provide outstanding neutrons screening performances for various energies. Indeed, these fibers contain a high proportion of hydrogen atoms that are known for their moderating effect toward incoming neutrons. For instance, UHMWPE reinforced epoxy/boron carbide hybrid composites displayed remarkable performances against fast neutrons with a macroscopic cross-section of $0.188 \mathrm{~cm}^{-1}$ equivalent to a mean free path of $3.7 \mathrm{~cm}$ [1]. Similarly, against thermal neutrons a macroscopic cross-section of $0.313 \mathrm{~cm}^{-1}$ equivalent to a mean free path of $2.2 \mathrm{~cm}$, was recorded [2]. It is also important to specify that boron particles were added because of their ability to absorb the energy of thermalized neutrons [3]. Furthermore, 


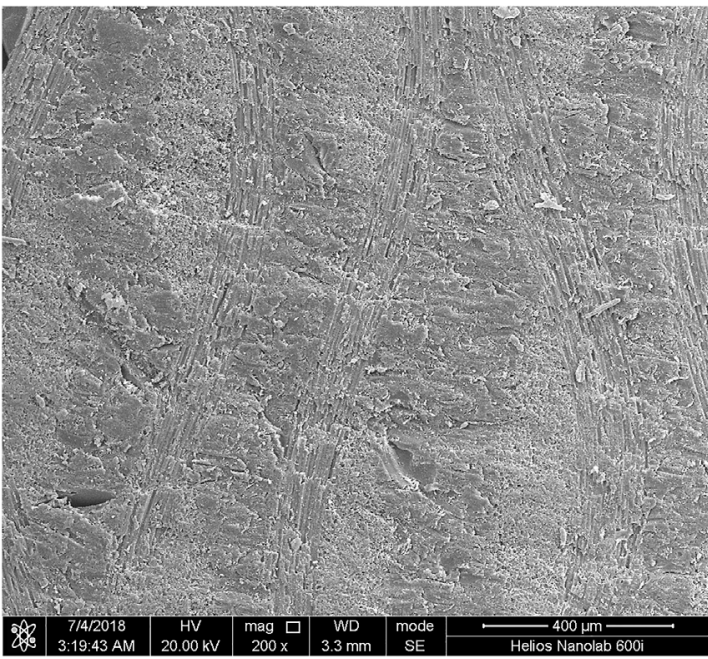

FIGURE 1 | SEM cross-sectional view of the studied hybrids.

Toyen et al. developed durable thermal neutron shields from samarium oxide $\left(\mathrm{Sm}_{2} \mathrm{O}_{3}\right)$ grafted UHMWPE fibers [4]. On the other hand, the low melting point (around $120^{\circ} \mathrm{C}$ ) of these fibers is a major drawback hindering the full exploitation of their shielding ability [5-8].

Para-aramid (Kevlar) fibers, similarly to UHMWPE fibers are mainly used in the field of ballistic to shield against various high velocity projectiles [9, 10]. Kevlar fibers start to decompose at temperatures in excess of $400^{\circ} \mathrm{C}$ and their atomic composition is somehow close to that of the UHMWPE fibers [11-13]. Thus, it came to our attention the study of the neutrons shielding properties of Kevlar based materials. Another objective is to develop, for the first time ever, a dual ballistic and nuclear protection designed for soldiers and personnel working in contact of theses radiations. In another words, the present work unravels the combination of the ballistic and nuclear shields into one hybrid composite capable of stopping high velocity projectiles and thermal neutrons.

\section{EXPERIMENTAL}

\section{Raw Materials and Composites Preparation}

The boron carbide (B4C) particles with a density of $2.5 \mathrm{~g} / \mathrm{cm}^{3}$ and an average diameter of $10 \mu \mathrm{m}$ were obtained from Sigma Aldrich (France). The typical diglycidyl ether of bisphenol A (DGEBA) epoxy and its cycloaliphatic amine hardener were purchased from Huntsman Corporation, France. The Kevlar fibers (K29) were supplied from DuPont, United States.

First, the epoxy monomers was dissolved in an appropriate solvent and the $\mathrm{B}_{4} \mathrm{C}$ particles were added in various amount ranging from 0 to $20 \mathrm{wt} . \%$ with an increment of $5 \mathrm{wt} . \%$. Then, the obtained mixtures were mechanically stirred for $4 \mathrm{~h}$ and further sonicated for

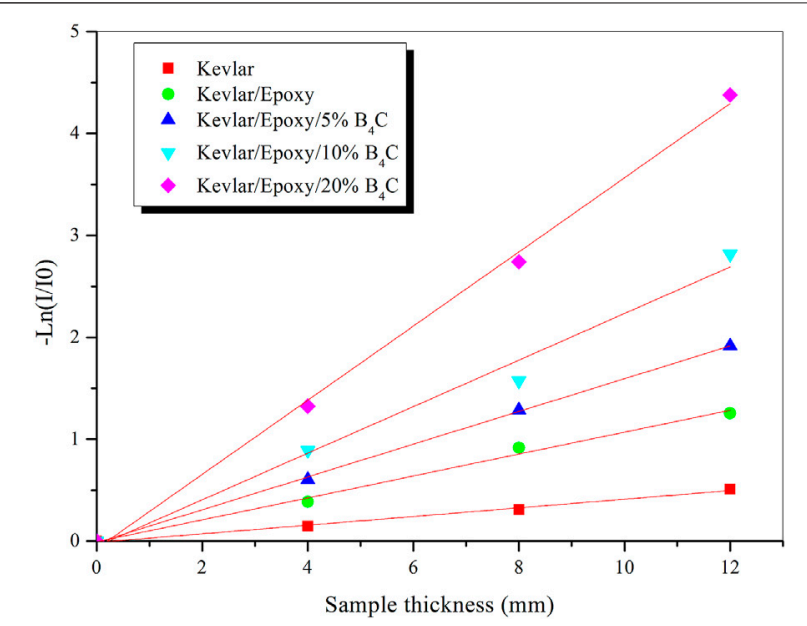

FIGURE 2 | Variation of $-\ln \left(1 / I_{0}\right)$ as a function of the thickness for the studied shields.

$30 \mathrm{~min}$. Afterwards, the solvent was allowed to evaporate and the hardener was added. It important to point out that the range of the $\mathrm{B}_{4} \mathrm{C}$ particles was chosen monitoring the resin maximum packing density and the overall mechanical performance of the composites.

The Kevlar 29 fibers were cut in the required dimensions and impregnated in the previously prepared mixtures with a 1:1 mass ratio of fabrics to matrix. Samples were subjected to a compression moulding technique, and cured for $24 \mathrm{~h}$ at room temperature. The obtained hybrid composites showed a high degree of structural integrity with negligible voids/porosities, as seen in Figure 1. For convenience, the cured hybrids were labelled as Kevlar/Epoxy $/ \mathrm{X} \mathrm{B}_{4} \mathrm{C}$, where $\mathrm{X}$ represents the amount of the particles.

\section{Neutron Shielding Tests}

The NUR nuclear reactor contains a Uranium-235 $\left({ }^{235} \mathrm{U}\right)$ and generates fast neutrons with an energy of about $2 \mathrm{MeV}$. These neutrons were directed to a filter to achieve monochromatic thermal neutrons with a wavelength of $0.47 \mathrm{~nm}$, equivalent to $3.7 \mathrm{meV}$. The samples of different thicknesses were placed between the thermal neutrons flux and the counter ( $3 \mathrm{He}$ proportional counter tube), at a distance of $15 \mathrm{~cm}$. The counter measures the number of transmitted neutrons by pulse counting, allowing the evaluation of the shielding parameters of the Kevlar/ Epoxy $/ \mathrm{B}_{4} \mathrm{C}$ composites.

Regardless of their energy, neutrons can interact with matter by absorption or scattering, following the below equation:

$$
I / I_{0}=e^{-\Sigma x}
$$

where $I_{0}$ refers to the initial neutron beam flux, I represents the neutron beam flux transmitted through a thickness $\mathrm{x}(\mathrm{cm})$ of the sample, $\Sigma$ is the total neutron attenuation coefficient. 

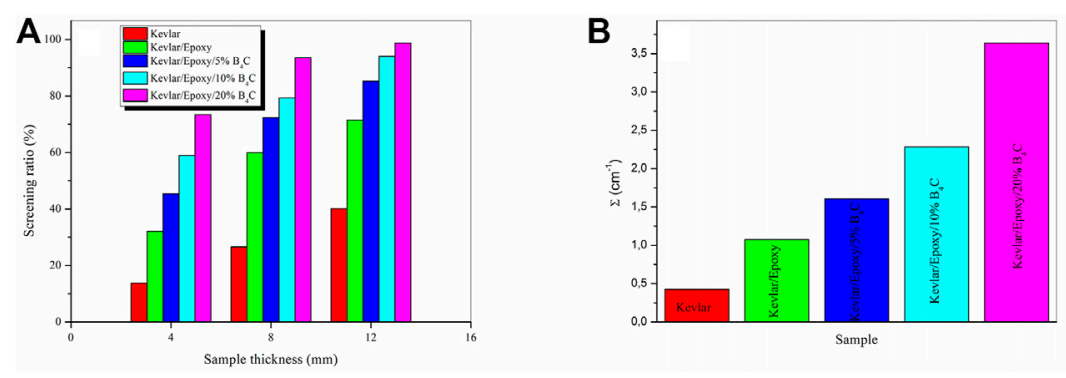

FIGURE 3 | Evolution of the screening ratios and the neutron attenuation coefficients.

TABLE 1 | $\Sigma$ data from this study as well as those from previous works.

\begin{tabular}{lcc} 
Sample & $\mathbf{\Sigma} \mathbf{( c m}^{\mathbf{- 1}} \mathbf{)}$ & References \\
\hline Wood/Natural Rubber/B ${ }_{2} \mathrm{O}_{3}$ & 1.980 & {$[14]$} \\
Boron trioxide/EPDM & 2.570 & {$[15]$} \\
Epoxy/Clay/B ${ }_{4} \mathrm{C}$ & 1.047 & {$[13]$} \\
$\mathrm{B}_{4} \mathrm{C} /$ epoxy & 0.347 & {$[16]$} \\
$\mathrm{Sm}_{2} \mathrm{O}_{3} /$ UHMWPE & 2.260 & {$[17]$} \\
Boric acid/EPDM & 0.534 & {$[19]$} \\
Ilmenite/epoxy & 0.198 & {$[18]$} \\
Boron-Containing Ores/epoxy & 0.182 & {$[20]$} \\
Lead-Boron Polythene B201 & 0.157 & {$[21]$} \\
Epoxy-Ferrochromium Slag & 0.346 & {$[22]$} \\
Epoxy/Molybdenum & 0.462 & {$[23]$} \\
Spectra/Epoxy & 0.189 & {$[2]$} \\
Spectra/Epoxy/10\% $\mathrm{B}_{4} \mathrm{C}$ & 0.289 & {$[2]$} \\
Spectra/Epoxy/20\% $\mathrm{B}_{4} \mathrm{C}$ & 0.313 & This work \\
Kevlar & 0.427 & This work \\
Kevlar/Epoxy & 1.074 & This work \\
Kevlar/Epoxy/5\% B ${ }_{4} \mathrm{C}$ & 1.607 & This work \\
Kevlar/Epoxy/10\% $\mathrm{B}_{4} \mathrm{C}$ & 2.284 & This work \\
Kevlar/Epoxy/20\% $\mathrm{B}_{4} \mathrm{C}$ & 3.638 & \\
& &
\end{tabular}

The screening or shielding ratio (S) and the mean free path (thickness to stop half of the original flux) can be calculated from the previous equation. Detailed equations can be found in our previous work $[1,2]$.

\section{RESULTS AND DISCUSSION}

Before assessing the neutron shielding efficiency of the Kevlar/Epoxy/ $\mathrm{B}_{4} \mathrm{C}$ hybrids, the number of neutrons passing through a thin Cadmium layer $(0.5 \mathrm{~mm})$ was counted. The obtained value was then subtracted from those obtained with the prepared hybrids. The next step consists on counting the number of neutrons passing through different thicknesses of the samples. The obtained results were then used to calculate the neutron attenuation coefficient $(\Sigma)$, according to Equation 1 and the obtained results are shown in Figure 2. Meanwhile, Figure 3A illustrates the variations of the screening ratio as a function of the fillers loading and Figure $3 \mathbf{B}$ shows the values of the neutrons attenuation coefficient $\Sigma$.

From the obtained results the neat Kevlar fibers showed remarkable shielding performances with a screening ratio of about $40 \%$ for a $12 \mathrm{~mm}$ thick sample. This is attributed to the atomic composition of these fibers containing a large proportion of low $\mathrm{Z}$ atoms, especially hydrogens which are well-known for their high interaction with neutrons of various energies. The addition of the epoxy resulted in better shielding performances. For instance, the screening ratio reached about $71 \%$ for a $12 \mathrm{~mm}$ thick sample. Besides providing lower $\mathrm{Z}$ atoms for higher interactions with neutrons, the epoxy resin allows the preparation of structural composites with improved mechanical properties. Meanwhile, with the addition of the $\mathrm{B}_{4} \mathrm{C}$ particles, the $\lambda$ reached the outstanding value of $0.191 \mathrm{~cm}$ for the $20 \mathrm{wt} . \% \mathrm{~B}_{4} \mathrm{C}$ loading. The boron atoms were added for their absorbing effect toward incoming neutrons. Indeed, boron atoms have a large macroscopic cross-section and mainly interact with neutrons by absorption. Therefore, this study confirmed that the combination of hydrogen and boron atoms in different forms can synergistically produce high performance shields.

To better asses the efficiency of the studied materials, a comparative study was conducted with practically all the available thermal neutrons shields [14-20]. The $\Sigma$ values obtained, in this work, as well as those gathered from various references are listed in Table 1. As clearly seen from this table, the developed shields surpass the majority of the already available shields. For instance, neat Kevlar fibers provided similar performances than Boric acid/EPDM composites [19]. Meanwhile, epoxy/Kevlar composite displayed comparable thermal neutron shielding than Epoxy/Clay/ $\mathrm{B}_{4} \mathrm{C}$ [13]. Additionally, the hybrid compositions offered the best results with a record value of $3.638 \mathrm{~cm}^{-1}$ for the hybrid Kevlar/Epoxy/20\% $\mathrm{B}_{4} \mathrm{C}$. More importantly, the Kevlar-based materials can provide supplementary protections against high velocity projectiles and stab threats for an optimal multi-threats protection. 


\section{CONCLUSION}

In this study, Kevlar fibers were introduced, for the first time ever, as interesting fillers for the development of advanced ballistic and nuclear shields. In fact, the obtained results confirmed to great potential of these materials to shield against thermal neutrons, directly originating from the NUR nuclear reactor. The lightweight and flexibility can be used to produce wearable ballistic and neutrons protections for soldiers and personals working in the vicinity of these radiations. The present study also opens up the way for further researches as high performance polymeric fibers can be seen as the future of the nuclear shielding materials.

\section{REFERENCES}

1. Mehelli O, Derradji M, Belgacemi R, Abdous S. Development of Lightweight and Highly Efficient Fast Neutrons Composites Shields Based on Epoxy, UHMWPE Fibres and boron Carbide Particles. Radiat Phys Chem (2021) 2021:109510. doi:10.1016/j.radphyschem.2021.109510

2. Mehelli O, Derradji M, Belgacemi R, Abdous S, Habes A, Liu W. Outstanding thermal Neutrons Shields Based on Epoxy, UHMWPE Fibers and boron Carbide Particles. Appl Radiat Isot (2021) 176:109837. doi:10.1016/j.apradiso.2021.109837

3. Rinard P. Neutron Interactions with Matter. In: Passive Nondestructive Assay of Nuclear Materials. Washington D.C: NUREG/CR-5550 (1991).

4. Toyen D, Wimolmala E, Sombatsompop N, Markpin T, Saenboonruang K. Sm2O3/UHMWPE Composites for Radiation Shielding Applications: Mechanical and Dielectric Properties under Gamma Irradiation and thermal Neutron Shielding. Radiat Phys Chem (2019) 164:108366. doi:10. 1016/j.radphyschem.2019.108366

5. Silverstein MS, Breuer O, Dodiuk H. Surface Modification of UHMWPE Fibers. J Appl Polym Sci (1994) 52:1785-95. doi:10.1002/app.1994.070521213

6. Zhang TG, Satapathy SS, Vargas-Gonzalez LR, Walsh SM. Ballistic Impact Response of Ultra-high-molecular-weight Polyethylene (UHMWPE). Compos structures (2015) 133:191-201. doi:10.1016/j.compstruct.2015.06.081

7. Shafiq M, Mehmood MS, Yasin T. On the Structural and Physicochemical Properties of Gamma Irradiated UHMWPE/silane Hybrid. Mater Chem Phys (2013) 143:425-33. doi:10.1016/j.matchemphys.2013.09.023

8. Wang J, Liang G, Zhao W, Lü S, Zhang Z. Studies on Surface Modification of UHMWPE Fibers via UV Initiated Grafting. Appl Surf Sci (2006) 253:668-73. doi:10.1016/j.apsusc.2005.12.165

9. Abu Talib AR, Abbud LH, Ali A, Mustapha F. Ballistic Impact Performance of Kevlar-29 and Al2O3 Powder/epoxy Targets under High Velocity Impact. Mater Des (2012) 35:12-9. doi:10.1016/j.matdes.2011.08.045

10. Chatzi EG, Koenig JL. Morphology and Structure of Kevlar Fibers: a Review. Polymer-Plastics Tech Eng (1987) 26:229-70. doi:10.1080/03602558708071938

11. Mehelli O, Derradji M, Belgacemi R, Zegaoui A, Khimeche K, Fantuzzi N, et al. Development of Highly Performant Hybrid Materials Based on Phthalonitrile Resin for a Simultaneous Ballistic and Nuclear Shielding Protection. High Performance Polymers (2021). doi:10.1177/2F0954008320954526

12. Singh TJ, Samanta S. Characterization of Kevlar Fiber and its Composites: A Review. Mater Today Proc (2015) 2:1381-7. doi:10.1016/j.matpr.2015.07.057

13. Sockalingam S, Chowdhury SC, Gillespie JW, Jr, Keefe M. Recent Advances in Modeling and Experiments of Kevlar Ballistic Fibrils, Fibers, Yarns and Flexible Woven Textile Fabrics - a Review. Textile Res J (2017) 87: 984-1010. doi:10.1177/0040517516646039

14. Kiani MA, Ahmadi SJ, Outokesh M, Adeli R, Mohammadi A. Preparation and Characteristics of epoxy/clay/B4C Nanocomposite at High Concentration of boron Carbide for Neutron Shielding Application. Radiat Phys Chem (2017) 141:223-8. doi:10.1016/j.radphyschem.2017.07.013

\section{DATA AVAILABILITY STATEMENT}

The original contributions presented in the study are included in the article/Supplementary Material, further inquiries can be directed to the corresponding author.

\section{AUTHOR CONTRIBUTIONS}

MD: Project administration; Resources; Supervision; Validation OM: Conceptualization; Investigation; Methodology; Writing original draft RB: Investigation; Validation; review and editing SA: Resources; Validation; review and editing.

15. Ninyong K, Wimolmala E, Sombatsompop N, Saenboonruang K. Potential Use of NR and wood/NR Composites as thermal Neutron Shielding Materials. Polym Test (2017) 59:336-43. doi:10.1016/j.polymertesting.2017.02.020

16. Özdemir T, Güngör A, Reyhancan İ. Flexible Neutron Shielding Composite Material of EPDM Rubber with boron Trioxide: Mechanical, thermal Investigations and Neutron Shielding Tests. Radiat Phys Chem (2017) 131:7-12.

17. Adeli R, Shirmardi SP, Ahmadi SJ. Neutron Irradiation Tests on B4C/epoxy Composite for Neutron Shielding Application and the Parameters Assay. Radiat Phys Chem (2016) 127:140-6. doi:10.1016/j.radphyschem.2016.06.026

18. El-Sayed Abdo A, El-Sarraf MA, Gaber FA. Utilization of Ilmenite/epoxy Composite for Neutrons and Gamma Rays Attenuation. Ann Nucl Energ (2003) 30:175-87. doi:10.1016/s0306-4549(02)00052-x

19. Özdemir T, Akbay I, Uzun H. Neutron Shielding of EPDM Rubber with Boric Acid: Mechanical, thermal Properties and Neutron Absorption Tests. Prog Nucl Energ (2016) 89:102-9.

20. Li ZF, Xue XX, Jiang T, Yang H, Zhou M. Study on the Properties of BoronContaining Ores/Epoxy Composites for Slow Neutron Shielding. Amr (2011) 201-203:2767-71. doi:10.4028/www.scientific.net/amr.201-203.2767

21. Lu J, Chen J. High Effective Shielding Material Lead-Baron Polyethylene. Nuclear Power Engineering (1994) 15:370-4.

22. Korkut T, Gencel O, Kam E, Brostow W. X-Ray, Gamma, and Neutron Radiation Tests on Epoxy-Ferrochromium Slag Composites by Experiments and Monte Carlo Simulation. International Journal of Polymer Analysis and Characterization (2013) 18:224-31.

23. Aygün B, Korkut T, Karabulut A, Gencel O, Karabulut A. Production and Neutron Irradiation Tests on a New Epoxy/Molybdenum Composite. International Journal of Polymer Analysis and Characterization (2015) 20: 323-9.

Conflict of Interest: The authors declare that the research was conducted in the absence of any commercial or financial relationships that could be construed as a potential conflict of interest.

Publisher's Note: All claims expressed in this article are solely those of the authors and do not necessarily represent those of their affiliated organizations, or those of the publisher, the editors and the reviewers. Any product that may be evaluated in this article, or claim that may be made by its manufacturer, is not guaranteed or endorsed by the publisher.

Copyright (C) 2022 Derradji, Mehelli, Belgacemi and Abdous. This is an open-access article distributed under the terms of the Creative Commons Attribution License (CC $B Y)$. The use, distribution or reproduction in other forums is permitted, provided the original author(s) and the copyright owner(s) are credited and that the original publication in this journal is cited, in accordance with accepted academic practice. No use, distribution or reproduction is permitted which does not comply with these terms. 